\title{
Pre-pregnancy maternal exposure to polybrominated and polychlorinated biphenyls and gestational diabetes: a prospective cohort study
}

\author{
Lindsay M. Jaacks ${ }^{*}$, Dana Boyd Barr², Rajeshwari Sundaram³ ${ }^{3}$ José M. Maisog ${ }^{4}$, Cuilin Zhang ${ }^{5}$
} and Germaine M. Buck Louis ${ }^{5}$

\begin{abstract}
Background: While several studies have shown an association between environmental pollutants and diabetes among non-pregnant adults, few studies have prospectively assessed the association among pregnant women. We estimated the association between maternal pre-pregnancy levels of a polybrominated biphenyl (PBB 153) and 36 polychlorinated biphenyls (PCBs) with gestational diabetes (GDM).

Methods: Data are from women (18-40 years) participating in a prospective cohort who achieved pregnancy lasting $\geq 24$ weeks gestation and completed monthly pregnancy journals $(n=258)$. Women were recruited between 2005 and 2007 from 16 counties in Michigan and Texas. Women who ever reported a physician diagnosis of high blood glucose in monthly pregnancy journals were categorized as having gestational diabetes $(n=28 ; 10.9 \%)$. Multivariable binary logistic regression was used to estimate odds ratios (OR) and $95 \%$ confidence intervals (Cls).

Results: There was no association between PBB 153 and GDM or any of the PCB congeners and GDM in unadjusted models. All associations remained non-significant with stepwise adjustment for age and waist-to-height ratio. Only with further adjustment for total serum lipids did the associations become significant, with lower levels of nine PCB congeners associated with GDM: 138, 153, 156, 167, 170, 172, 178, 180, and 194. The adjusted ORs for PCBs 170 and 180 were the strongest: $0.40(0.18,0.88)$ and $0.41(0.19,0.87)$, respectively.

Conclusions: Pre-pregnancy levels of PCBs were not consistently associated with development of GDM in this prospective cohort of U.S. women. Interestingly, we found that although women with GDM had higher mean prepregnancy circulating lipid levels compared to women without GDM, they had lower wet weight circulating levels of many PCBs. More research is needed to understand the dynamic fluctuations of PCBs and other persistent organic pollutants between lipid compartments in women preparing to conceive and throughout pregnancy.
\end{abstract}

Keywords: Persistent organic pollutants, Lipids, Diabetes, Pregnancy

\footnotetext{
* Correspondence: ljaacks@emory.edu

${ }^{1}$ Hubert Department of Global Health, Rollins School of Public Health, Emory University, Claudia Nance Rollins Building 7040-I, 1518 Clifton Rd NE, Atlanta, GA 30322, USA

Full list of author information is available at the end of the article
} 


\section{Background}

Gestational diabetes (GDM) is common in the United States, affecting as many as $9.2 \%$ of live births [1]. GDM is associated with increased risk of type 2 diabetes in the mother [2] and unfavorable metabolic phenotypes in the offspring [3-8]; thus, GDM prevention is an important goal of larger efforts to address the type 2 diabetes epidemic. Increased maternal age and pre-pregnancy obesity are established risk factors for GDM [9-11]. Only a few studies have explored the role of environmental chemicals in the etiology of GDM. The U.S. Agricultural Health Study found a significant association between self-reported use of agricultural pesticides (but not residential pesticides) during the first trimester of pregnancy and GDM: odds ratio (OR) and $95 \%$ confidence interval (CI), $2.2(1.5,3.3)[12]$. A study of women in the French West Indies found no significant association between maternal serum chlordecone levels at delivery and GDM recorded in medical records: OR (95\% CI), 0.7 $(0.5,1.1)[13]$. A study of pre-pregnancy serum perfluorooctanoic acid in the U.S. general population found a significant positive association with GDM risk: OR (95 \% CI), $1.86(1.14,3.02)$ [14].

To our knowledge, no study has evaluated the association between polybrominated biphenyls (PBBs) and GDM, and only a few studies have evaluated the association between PBBs and diabetes among non-pregnant adults. For example, a 25-year follow-up of the Michigan PBB Cohort did not find a significant association between serum $\mathrm{PBB}$ levels and incident type 2 diabetes [15]. Similarly, low dose exposure to PBB among individuals without diabetes was not significantly associated with insulin resistance measured 20 years later [16]. In contrast, low dose exposure to PBB in NHANES 2003-2004 (a cross-sectional sample) was significantly associated with type 2 diabetes [17].

While several studies have evaluated the association between polychlorinated biphenyls (PCBs) and type 2 diabetes, to our knowledge, none have evaluated the association with GDM. A recent meta-analysis of six prospective studies (four in the United States, one in Sweden, and one in Taiwan) found that higher levels of total serum PCBs were significantly associated with an increased risk of type 2 diabetes in non-pregnant men and women [18].

Clearly, a significant gap remains in the scientific literature relating environmental chemical exposures and GDM. The objective of this analysis was to estimate the association of pre-pregnancy PBB 153 and 36 PCB congeners with GDM.

\section{Methods}

\section{Study sample}

Data are from a prospective cohort, the Longitudinal Investigation of Fertility and the Environment (LIFE)
Study [19]. The sample was recruited between 2005 and 2007 from 16 counties in Michigan and Texas. The Texan Parks and Wildlife Department's angler database and, in Michigan, a commercially available marketing database, were used to identify individuals to whom recruitment materials should be mailed. Individuals were screened for eligibility via telephone interview within 2 weeks of this mailing. Eligibility criteria included: (1) married or in a committed relationship, (2) aged 18-40 years for women and $\geq 18$ years for men, (3) self-reported menstrual cycles within the range of 21-42 days, (4) no hormonal birth control injections in the past 12 months, and (5) English or Spanish-speaking. Of 51,715 individuals screened via this process, only 1188 (2.3\%) were eligible. Among eligible participants, 501 enrolled in the study and 347 achieved pregnancy of which 258 (74 \%) women completed monthly pregnancy journals for their pregnancies lasting $\geq 24$ weeks gestation. This gestational age cut-point is consistent with the recommended time to start universal screening for GDM [20].

Following a baseline study visit, which was conducted by a nurse and assistant at the participants' home, women were followed daily until a positive pregnancy test and through the first seven post-conception weeks of pregnancy, and then monthly until delivery. Approval for use of human subjects was obtained from all collaborating institutions and all participants provided informed consent.

\section{Exposure assessment}

Laboratory assessment was conducted by the Division of Laboratory Sciences in the National Center for Environmental Health at the Centers for Disease Control and Prevention. Pre-pregnancy, non-fasting blood samples were collected during the baseline study visit into ethylenediaminetetraacetic acid (EDTA) tubes, which were spun down and aliquoted immediately, and the plasma stored at $\leq 70{ }^{\circ} \mathrm{C}$. The laboratory tested and selected all venipuncture and collection equipment, assuring that they were free of persistent organic pollutants (POPs).

High performance gas chromatography-high resolution mass spectrometry at 10,000 resolution was used to quantify pre-pregnancy serum concentrations of one PBB congener and 36 PCB congeners [21]. An enzymatic summation method was used to quantify serum concentrations of total cholesterol, nonesterified cholesterol, triglycerides, and phospholipids [22]. Total lipid was calculated using the Phillips formula [23].

PBB, PCB, and total lipid values were natural logtransformed $(x+1)$ and rescaled by their standard deviation to aid interpretation of results. The mean (SD) limit of detection (LOD) across samples was 0.0025 (0.0002) ng/g serum for all PCB congeners except PCB 28 (LOD mean [SD] of 0.0082 [0.0006] ng/g serum) and 
PCB 52 (LOD mean [SD] of 0.0040 [0.0003] ng/g serum). The LOD mean (SD) for PBB 153 was 0.0026 $(0.0005) \mathrm{ng} / \mathrm{g}$ serum. We did not substitute concentrations below the limit of detection, as this practice can introduce bias in estimation of human health outcomes $[24,25]$. We also made the a priori decision not to sum all $36 \mathrm{PCB}$ congeners given that this data reduction technique assumes that summed components act via the same mechanism and elicit the same effects [26]. We did, however, conduct a sensitivity analysis to evaluate the effects of the sum of dioxin-like PCB congeners (congeners 105, 118, 156, 157, 167, and 189), and the sum of non-dioxin-like PCB congeners (remaining 30 congeners) [27]. For seven PCB congeners $(49,52,87$, $128,149,151$, and 189), $>90 \%$ of samples had levels below the LOD. When these PCB congeners were dichotomized as above versus below the LOD, no significant associations with GDM were observed in either unadjusted or adjusted analyses, thus they were excluded from further analysis.

\section{Outcome assessment}

In monthly pregnancy journals, which were designed to be consistent with recommendations of the American Congress for Obstetricians and Gynecologists for antenatal care including the time of GDM, women were instructed to record whether their obstetrical health care provider told them they had high blood sugar associated with pregnancy. Women were also encouraged to take their pregnancy journal with them to doctor's appointments. Women who ever reported a physician diagnosis of high blood glucose during pregnancy that was not pre-existing were categorized as having gestational diabetes $(n=28 ; 10.9 \%)$.

\section{Covariate assessment}

Women were also interviewed about their lifestyle and medical/reproductive histories followed by anthropometric assessment (height, weight, and waist and hip circumferences) using an established protocol [28] during the baseline study visit. Pre-pregnancy body mass index (BMI) was calculated as measured weight in kilograms divided by height in meters-squared [29] and categorized as BMI $<25.0 \mathrm{~kg} / \mathrm{m}^{2}$ versus $\mathrm{BMI} \geq 25.0 \mathrm{~kg} / \mathrm{m}^{2}$ (overweight or obese) [30]. Two markers of visceral adiposity were used: (1) high waist circumference, defined as a waist circumference $>88 \mathrm{~cm}$ [31, 32] and (2) high waist-to-height ratio, defined as a waist-to-height ratio $>0.5$ [33].

Gestational weight gain was calculated as the difference between measured pre-pregnancy weight and the last selfreported pregnancy weight from monthly pregnancy journals. Women were classified into three categories based on pre-pregnancy BMI-specific U.S. Institute of Medicine Guidelines [34]: (1) gained less than ideal weight, (2) gained ideal weight, and (3) gained more than ideal weight.

\section{Statistical analysis}

All analyses were conducted using SAS software version 9.4 (SAS Institute, Cary, North Carolina). Markov Chain Monte Carlo methods were implemented to impute missing chemical and lipid data $(\leq 4 \%$ missing, see Additional file 1) using other chemical exposures [35, 36]. A total of 10 multiple imputations were computed. Descriptive statistics were used to explore the distributions of exposures and covariates. Bivariate associations between covariates and GDM were evaluated using chi-square tests and analysis of variance (ANOVA). Bivariate associations between covariates and chemicals were evaluated using ANOVA and correlation coefficients. SAS PROC MIANALYZE was used to combine means and standard deviations from the multiple imputations. Correlation coefficients from the multiple imputations were combined using Fisher's $\mathrm{z}$ transformation [37, 38]. Scatterplots were used to visualize the association between chemicals and lipids stratified by GDM status.

Multivariable binary logistic regression was used to estimate ORs and $95 \%$ CIs for the association between PBB 153 and each of the 36 PCB congeners with GDM. Separate models were run for each chemical or congener. SAS

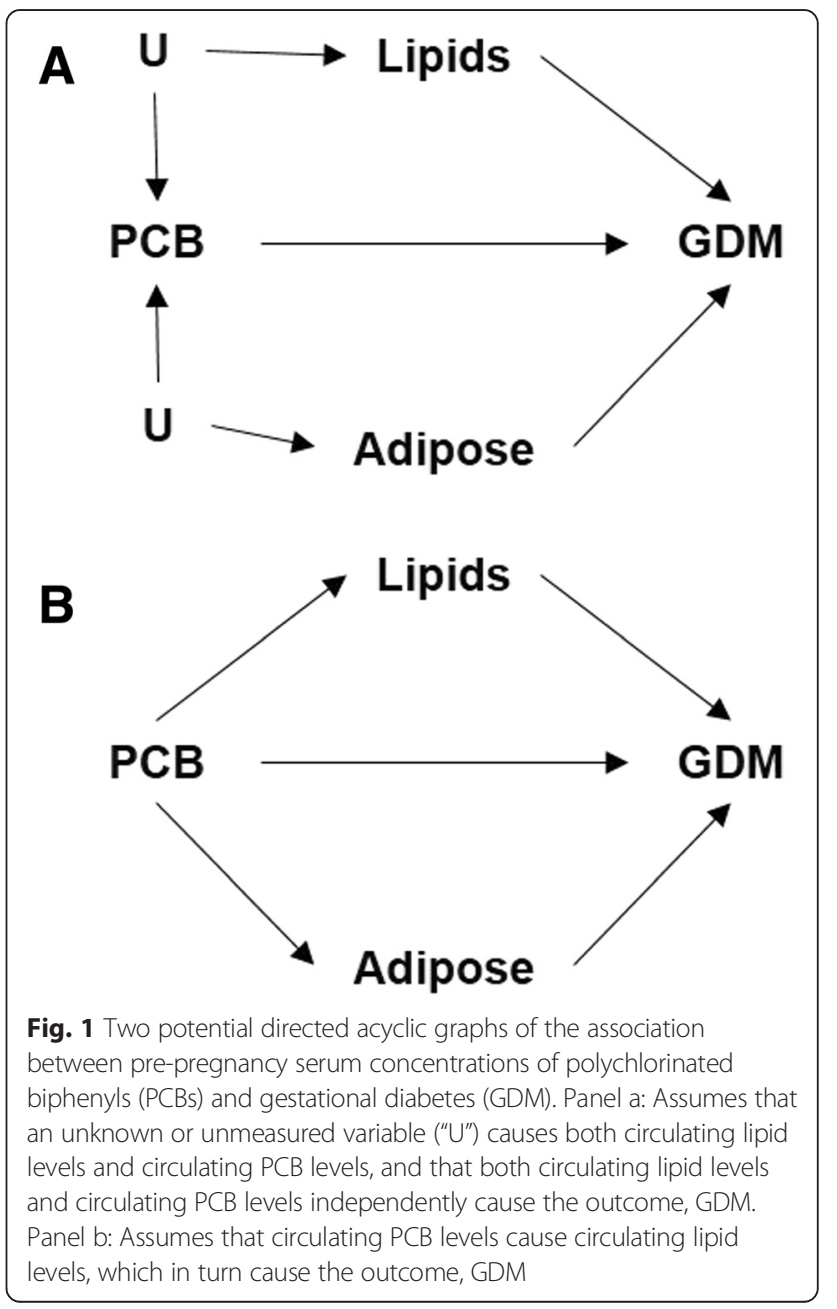


Table 1 Characteristics of participants according to gestational diabetes (GDM) status

\begin{tabular}{|c|c|c|c|}
\hline & $\begin{array}{l}\text { Non-GDM } \\
(n=230)\end{array}$ & $\begin{array}{l}\text { GDM } \\
(n=28)\end{array}$ & $P$-value \\
\hline Pre-pregnancy age (years) & $29.6(3.8)$ & $30.2(2.9)$ & 0.42 \\
\hline \multicolumn{4}{|l|}{ Pre-pregnancy age category (\%) } \\
\hline Age $\leq 25$ years & $14.4(33)$ & $3.6(1)$ & 0.11 \\
\hline Age $>25$ years & $85.7(197)$ & $96.4(27)$ & \\
\hline Non-fasting serum lipids $(\mathrm{mg} / \mathrm{dl})^{\mathrm{a}}$ & $607.1(113.6)$ & $678.7(122.7)$ & 0.0009 \\
\hline Pre-pregnancy BMI (kg/m²) & $26.1(6.4)$ & $27.0(4.6)$ & 0.47 \\
\hline \multicolumn{4}{|l|}{ Pre-pregnancy BMI status (\%) } \\
\hline$<25 \mathrm{~kg} / \mathrm{m}^{2}$ & $54.8(126)$ & $46.4(13)$ & 0.40 \\
\hline$\geq 25 \mathrm{~kg} / \mathrm{m}^{2}$ & $45.2(104)$ & $53.6(15)$ & \\
\hline $\begin{array}{l}\text { Pre-pregnancy waist } \\
\text { circumference }(\mathrm{cm})\end{array}$ & $87.8(14.8)$ & $90.2(13.2)$ & 0.41 \\
\hline \multicolumn{4}{|l|}{$\begin{array}{l}\text { Pre-pregnancy waist } \\
\text { circumference status (\%) }\end{array}$} \\
\hline$\leq 88 \mathrm{~cm}$ & $60.9(140)$ & $57.1(16)$ & 0.70 \\
\hline$>88 \mathrm{~cm}$ & $39.1(90)$ & $42.9(12)$ & \\
\hline \multicolumn{4}{|l|}{$\begin{array}{l}\text { Pre-pregnancy waist-to-height } \\
\text { ratio status (\%) }\end{array}$} \\
\hline$\leq 0.5$ & $40.0(92)$ & $21.4(6)$ & 0.06 \\
\hline$>0.5$ & $60.0(138)$ & $78.6(22)$ & \\
\hline \multicolumn{4}{|l|}{ Parity and gravidity (\%) } \\
\hline Never pregnant & $41.3(95)$ & $35.7(10)$ & 0.85 \\
\hline Pregnant without live birth & $7.0(16)$ & $7.1(2)$ & \\
\hline Pregnant with previous birth & $51.7(119)$ & $57.1(16)$ & \\
\hline \multicolumn{4}{|l|}{ Race/ethnicity (\%) } \\
\hline Non-Hispanic white & $85.7(197)$ & $75.0(21)$ & 0.14 \\
\hline Other & $14.4(33)$ & $25.0(7)$ & \\
\hline \multicolumn{4}{|l|}{ Pre-pregnancy smoking status (\%) } \\
\hline Yes & $6.5(15)$ & $7.1(2)$ & 0.90 \\
\hline No & $93.5(215)$ & $92.9(26)$ & \\
\hline \multicolumn{4}{|c|}{ Weight gain from 15-19 years old to pre-pregnancy (\%) } \\
\hline$<10 \mathrm{~kg}$ & $46.1(106)$ & $32.1(9)$ & 0.05 \\
\hline $10-19.9$ kg & $31.7(73)$ & $25.0(7)$ & \\
\hline$\geq 20 \mathrm{~kg}$ & $22.2(51)$ & $42.9(12)$ & \\
\hline \multicolumn{4}{|l|}{ Pregnancy weight gain (\%) ${ }^{c}$} \\
\hline Gained recommended weight & $28.2(59)$ & $35.7(10)$ & 0.05 \\
\hline $\begin{array}{l}\text { Gained }<\text { recommended } \\
\text { weight }\end{array}$ & $30.6(64)$ & $46.4(13)$ & \\
\hline $\begin{array}{l}\text { Gained }>\text { recommended } \\
\text { weight }\end{array}$ & $41.2(86)$ & $17.9(5)$ & \\
\hline \multicolumn{4}{|l|}{ Maternal birth weight (\%) } \\
\hline Low $(<2000 \mathrm{~g})$ & $1.7(4)$ & $14.3(4)$ & 0.001 \\
\hline Normal (2000-4000 g) & $89.6(206)$ & $82.1(23)$ & \\
\hline High (>4000 g) & $8.7(20)$ & $3.6(1)$ & \\
\hline
\end{tabular}

Table 1 Characteristics of participants according to gestational diabetes (GDM) status (Continued)

Maternal history of GDM (\%)

\begin{tabular}{llll} 
Yes & $0.9(2)$ & $14.3(4)$ & $<0.0001$ \\
No & $99.1(228)$ & $85.7(24)$ & \\
\hline
\end{tabular}

Values are mean (SD) or \% ( $n$ )

${ }^{a}$ Estimated from the Phillips 1989 equation

${ }^{\mathrm{b}} P$-value from chi-square test for categorical variables and analysis of variance for continuous variables

'Gestational weight gain status defined according to the U.S. Institute of Medicine Guidelines as: pre-pregnancy BMI $<18.5 \mathrm{~kg} / \mathrm{m}^{2}, 11.3-15.9 \mathrm{~kg}$; pre-pregnancy BMI $\geq 18.5$ and $<25 \mathrm{~kg} / \mathrm{m}^{2}, 12.7-18.1 \mathrm{~kg}$; pre-pregnancy BMI $\geq 25$ and $<30 \mathrm{~kg} / \mathrm{m}^{2}, 6.8-11.3 \mathrm{~kg}$; pre-pregnancy BMI $\geq 30 \mathrm{~kg} / \mathrm{m}^{2}, 5.0-9.1 \mathrm{~kg}$

PROC MIANALYZE was used to calculate the average of the 10 complete-data estimates from the multiple imputations. The variance of this estimate was the sum of the between- and within-imputation variances. Two models were reported for PBB 153 and each of the PCB congeners: unadjusted and adjusted for maternal pre-pregnancy age, waist-to-height ratio, and total serum lipids, all specified continuously. These two models reflect two hypothesized directed acyclic graphs (Fig. 1). The first directed acyclic graph (Fig. 1a) assumes that an unmeasured variable ("U") causes both circulating lipid levels and circulating PCB levels, and that both circulating lipid levels and circulating PCB levels independently cause the outcome, GDM. This is the traditional confounding structure and the effect estimate is least biased when adjusted for total serum lipids [39]. The second directed acyclic graph (Fig. 1b) assumes that circulating PCB levels cause circulating lipid levels, which in turn cause the outcome, GDM. In this case, the effect estimate is least biased when unadjusted for total serum lipids [39]. Other confounders were selected according to the following three properties: associated with the exposure (i.e. chemicals), associated with the disease (i.e. GDM), and not on the causal pathway between exposure and disease [40]. As this was an exploratory analysis, $p$-values were not adjusted for multiple testing.

\section{Results}

Compared to women who did not develop GDM, women who developed GDM were more likely to report a weight gain of $\geq 20 \mathrm{~kg}$ since adolescence; having themselves been a low-birth-weight baby; a history of GDM during past pregnancies; and gaining less than the recommended amount of weight during the current pregnancy (Table 1). There were no significant differences in age, parity/gravidity, or smoking/tobacco use, though women who developed GDM tended to be $>25$ years old and a race/ethnicity other than non-Hispanic white. With respect to pre-pregnancy anthropometrics, women who developed GDM tended to have greater visceral adiposity, estimated using waist-to-height ratio: $78.6 \%$ of GDM women were classified as having high waist-to- 
Table 2 Association of pre-pregnancy serum polybrominated and polychlorinated biphenyl levels with gestational diabetes $(n=258)$

\begin{tabular}{|c|c|c|}
\hline & Unadjusted $^{a}$ & Adjusted $^{b}$ \\
\hline \multicolumn{3}{|c|}{ Polybrominated biphenyl (rescaled, natural-log transformed) } \\
\hline 153 & $0.73(0.37,1.43)$ & $0.68(0.31,1.49)$ \\
\hline \multicolumn{3}{|c|}{ Polychlorinated biphenyls (rescaled, natural-log transformed) } \\
\hline 28 & $0.91(0.42,1.98)$ & $0.90(0.24,3.31)$ \\
\hline 44 & $0.83(0.20,3.43)$ & $0.88(0.24,3.23)$ \\
\hline 66 & $0.96(0.58,1.60)$ & $0.96(0.49,1.87)$ \\
\hline 74 & $0.89(0.44,1.81)$ & $0.52(0.13,2.06)$ \\
\hline 99 & $1.00(0.67,1.48)$ & $0.78(0.48,1.29)$ \\
\hline 101 & $1.05(0.75,1.48)$ & $1.00(0.69,1.47)$ \\
\hline 105 & $1.09(0.76,1.57)$ & $0.88(0.57,1.36)$ \\
\hline 110 & $0.88(0.54,1.44)$ & $0.82(0.46,1.46)$ \\
\hline 114 & $0.69(0.40,1.21)$ & $0.53(0.28,1.00)$ \\
\hline 118 & $1.02(0.69,1.50)$ & $0.81(0.51,1.29)$ \\
\hline 138 & $0.75(0.46,1.24)$ & $0.53(0.29,0.99)$ \\
\hline 146 & $0.73(0.43,1.22)$ & $0.53(0.28,1.02)$ \\
\hline 153 & $0.70(0.41,1.21)$ & $0.48(0.24,0.98)$ \\
\hline 156 & $0.57(0.32,1.02)$ & $0.42(0.21,0.87)$ \\
\hline 157 & $0.70(0.43,1.13)$ & $0.57(0.32,1.03)$ \\
\hline 167 & $0.57(0.31,1.06)$ & $0.42(0.21,0.84)$ \\
\hline 170 & $0.61(0.33,1.12)$ & $0.40(0.18,0.88)$ \\
\hline 172 & $0.60(0.34,1.09)$ & $0.44(0.23,0.86)$ \\
\hline 177 & $0.73(0.31,1.69)$ & $0.46(0.17,1.25)$ \\
\hline 178 & $0.66(0.36,1.18)$ & $0.50(0.25,0.98)$ \\
\hline 180 & $0.59(0.32,1.08)$ & $0.41(0.19,0.87)$ \\
\hline 183 & $0.91(0.56,1.50)$ & $0.65(0.31,1.35)$ \\
\hline 187 & $0.68(0.34,1.33)$ & $0.48(0.21,1.09)$ \\
\hline 194 & $0.68(0.42,1.12)$ & $0.50(0.27,0.95)$ \\
\hline 195 & $0.76(0.47,1.23)$ & $0.63(0.37,1.07)$ \\
\hline 196 & $0.79(0.48,1.30)$ & $0.60(0.33,1.11)$ \\
\hline 201 & $0.75(0.44,1.27)$ & $0.62(0.33,1.17)$ \\
\hline 206 & $0.91(0.58,1.41)$ & $0.72(0.41,1.27)$ \\
\hline 209 & $1.09(0.75,1.59)$ & $0.92(0.61,1.41)$ \\
\hline
\end{tabular}

Values are odds ratios (95\% confidence intervals) from multivariable binary logistic regression with no gestational diabetes as the referent category. $P$-values $<0.05$ are bolded

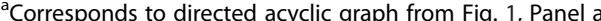

${ }^{\mathrm{b}}$ Adjusted for total serum lipids estimated from the Phillips 1989 equation, age, and waist-to-height ratio, all specified continuously. Corresponds to directed acyclic graph from Fig. 1 , Panel b

height ratios compared to only $60.0 \%$ of non-GDM women. However, there was no statistically significant difference in BMI status: $53.6 \%$ of GDM women were classified as overweight or obese compared to $45.2 \%$ of non-GDM women.

There was no association between PBB 153 and GDM or any of the PCB congeners and GDM in unadjusted models (Table 2). All associations remained nonsignificant with stepwise adjustment for age and waist-toheight ratio (data not shown). Only with further adjustment for total serum lipids did the associations become significant, with lower levels of nine PCB congeners associated with GDM: 138, 153, 156, 167, 170, 172, 178, 180, and 194. The adjusted ORs (95\% CI) for PCBs 170 and 180 were the strongest: $0.40(0.18,0.88)$ and $0.41(0.19$, $0.87)$, respectively. The adjusted OR $(95 \% \mathrm{CI})$ for the sum of dioxin-like PCB congeners was $0.65(0.37,1.15)$ and for the sum of non-dioxin-like PCB congeners it was 0.37 $(0.13,1.04)$. When models were adjusted for individual lipid components rather than total lipids, results were attenuated towards the null but remained significant for PCBs 156, 167, 170, 172, and 180 (data not shown). Results were also consistent in a complete-case analysis and with additional adjustment for weight gain during current pregnancy, history of gestational diabetes, weight gain since age 15-19 years, or study site (data not shown).

Women who went on to develop GDM had higher pre-pregnancy levels of serum lipids: mean (SD) of 678.7 (122.7) $\mathrm{mg} / \mathrm{dl}$ compared to 607.1 (113.6) $\mathrm{mg} / \mathrm{dl}$ among women who did not develop GDM. When the association between lipids and select PCBs was plotted according to GDM status, while a correlation between variables was clearly evident among women with GDM, it was shifted relative to women without GDM such that lipids were higher and PCBs lower (Fig. 2).

Several PCB congeners were positively associated with both age and serum lipids including: $99,105,118,138$, 146, 153, and all PCBs >167 except PCB 201 (Table 3). Several PCBs also tended to be negatively associated with BMI and waist-to-height ratio, including congeners 156, 157, 180, and 209.

When models were stratified by visceral adiposity status (high versus normal waist-to-height ratio) and BMI status, differences in associations between groups were only slight and all confidence intervals were overlapping making it difficult to conclude anything about effect modification by body fat (Fig. 3). When models were stratified by lipid status (above versus below the median for the entire sample population), and then adjusted for age and waist-to-height ratio, the association was stronger among those with lower lipids consistently across PCB congeners, but again, all confidence intervals were overlapping (Fig. 4).

\section{Discussion}

Pre-pregnancy levels of PCBs were not consistently associated with GDM in this prospective cohort of U.S. women. Interestingly, we found that although women who developed GDM had higher mean pre-pregnancy circulating lipid levels compared to women who did not develop GDM, they had lower circulating levels of PCBs. 

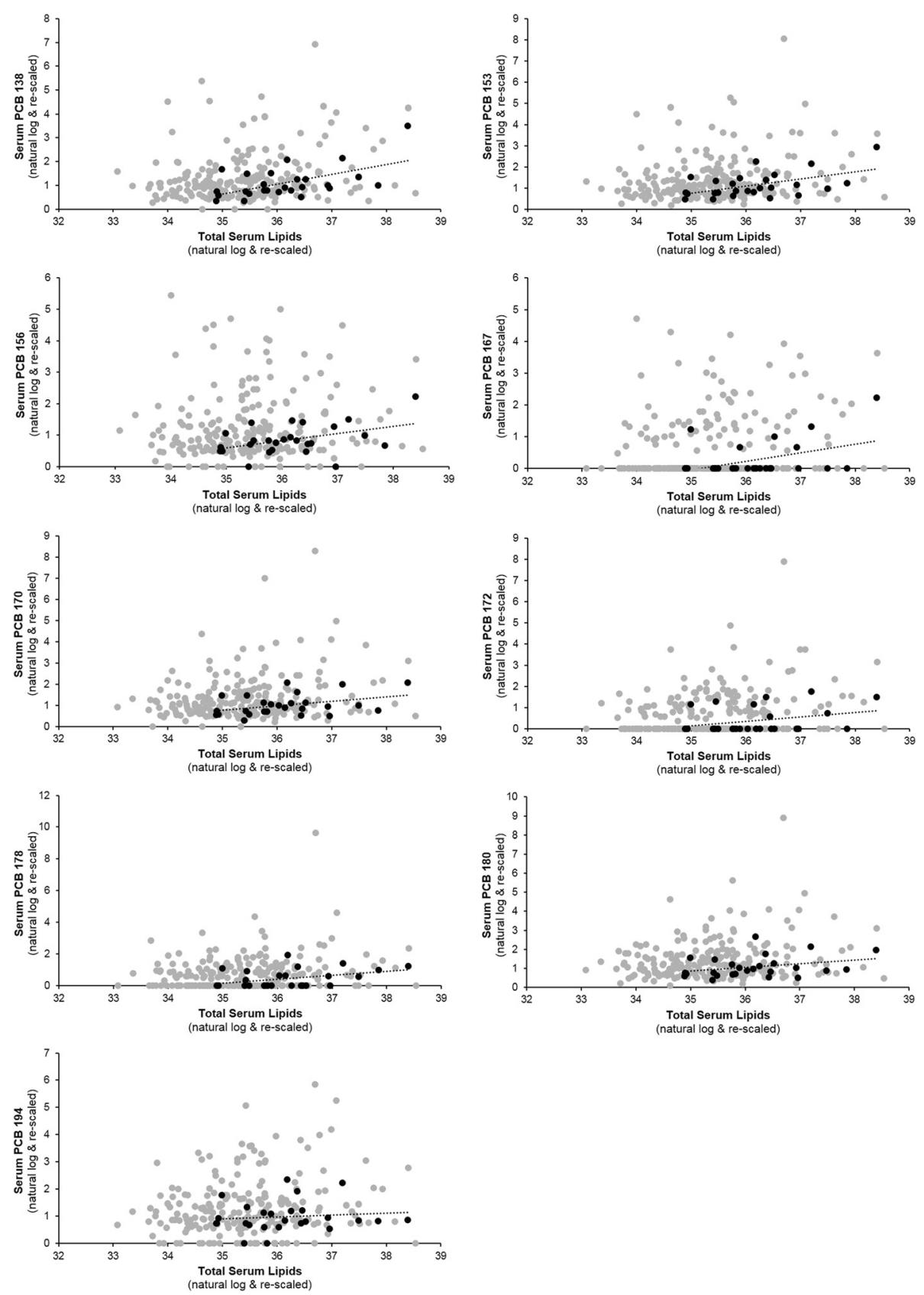

Fig. 2 Scatterplot of select pre-pregnancy serum polychlorinated biphenyl (PCB) congeners and total serum lipids for women with (black circles) and without (gray circles) gestational diabetes

Thus, when multivariable models were adjusted for lipids, women who developed GDM had significantly lower pre-pregnancy levels of circulating PCBs (congeners $138,153,156,167,170,172,178,180$, and 194). Because lipids are an important risk factor for the outcome, GDM, careful consideration of the method of lipid adjustment is warranted. If some unmeasured factor affects both circulating PCB and lipid levels, then the least biased models are those adjusting for total serum lipids [39]. However, if the opposite is true and circulating PCBs affect circulating lipids, as causal pathway analysis suggests [41], then the most unbiased models are those that do not adjust for circulating lipids [39]-all of these associations were null in our study.

Previous studies have also reported that serum lipid levels in pregnancy were significantly associated with GDM risk, for instance, women who develop GDM have higher serum triglyceride levels early on in pregnancy 
Table 3 Correlation between pre-pregnancy serum polybrominated and polychlorinated biphenyl levels and age, body mass index (BMI), waist-to-height ratio (WHR), and total serum lipids $(n=258)$

\begin{tabular}{|c|c|c|c|c|}
\hline & Age (years) & BMI $\left(\mathrm{kg} / \mathrm{m}^{2}\right)$ & WHR & Lipids $^{\mathrm{a}}$ \\
\hline \multicolumn{5}{|c|}{ Polybrominated biphenyl (rescaled, natural-log transformed) } \\
\hline 153 & $0.13(0.03)$ & $0.01(0.89)$ & $-0.04(0.50)$ & $-0.03(0.59)$ \\
\hline \multicolumn{5}{|c|}{ Polychlorinated biphenyls (rescaled, natural-log transformed) } \\
\hline 28 & $-0.03(0.69)$ & $0.07(0.26)$ & $0.07(0.28)$ & $-0.04(0.55)$ \\
\hline 44 & $-0.02(0.73)$ & $0.07(0.28)$ & $0.06(0.33)$ & $-0.05(0.41)$ \\
\hline 66 & $-0.02(0.78)$ & $0.07(0.26)$ & $0.07(0.27)$ & $-0.02(0.71)$ \\
\hline 74 & $0.07(0.25)$ & $0.06(0.31)$ & $0.05(0.46)$ & $0.04(0.58)$ \\
\hline 99 & $0.23(0.0003)$ & $0.02(0.73)$ & $0.00(0.99)$ & $0.19(0.004)$ \\
\hline 101 & $0.04(0.55)$ & $0.08(0.19)$ & $0.10(0.10)$ & $0.06(0.31)$ \\
\hline 105 & $0.20(0.001)$ & $0.06(0.32)$ & $0.08(0.22)$ & $0.23(0.0004)$ \\
\hline 110 & $0.06(0.36)$ & $0.07(0.26)$ & $0.09(0.17)$ & $0.01(0.83)$ \\
\hline 114 & $0.18(0.003)$ & $-0.02(0.75)$ & $0.00(0.94)$ & $0.09(0.18)$ \\
\hline 118 & $0.25(0.0001)$ & $0.03(0.59)$ & $0.04(0.57)$ & $0.21(0.001)$ \\
\hline 138 & $0.27(<.0001)$ & $-0.03(0.66)$ & $-0.03(0.64)$ & $0.20(0.002)$ \\
\hline 146 & $0.29(<.0001)$ & $-0.05(0.38)$ & $-0.05(0.47)$ & $0.15(0.02)$ \\
\hline 153 & $0.28(<.0001)$ & $-0.08(0.18)$ & $-0.07(0.30)$ & $0.18(0.005)$ \\
\hline 156 & $0.19(0.002)$ & $-0.17(0.007)$ & $-0.14(0.03)$ & $0.07(0.25)$ \\
\hline 157 & $0.21(0.0006)$ & $-0.15(0.01)$ & $-0.13(0.05)$ & $0.03(0.68)$ \\
\hline 167 & $0.26(<.0001)$ & $-0.01(0.88)$ & $-0.02(0.77)$ & $0.13(0.04)$ \\
\hline 170 & $0.27(<.0001)$ & $-0.11(0.07)$ & $-0.10(0.12)$ & $0.17(0.007)$ \\
\hline 172 & $0.27(<.0001)$ & $0.00(0.99)$ & $0.00(0.99)$ & $0.19(0.004)$ \\
\hline 177 & $0.17(0.007)$ & $0.02(0.69)$ & $0.03(0.60)$ & $0.15(0.02)$ \\
\hline 178 & $0.22(0.0003)$ & $-0.06(0.34)$ & $-0.04(0.51)$ & $0.15(0.02)$ \\
\hline 180 & $0.30(<.0001)$ & $-0.12(0.05)$ & $-0.12(0.07)$ & $0.15(0.02)$ \\
\hline 183 & $0.22(0.0004)$ & $0.04(0.49)$ & $0.04(0.49)$ & $0.20(0.002)$ \\
\hline 187 & $0.24(0.0001)$ & $0.00(0.97)$ & $-0.01(0.92)$ & $0.15(0.02)$ \\
\hline 194 & $0.38(<.0001)$ & $-0.10(0.10)$ & $-0.13(0.03)$ & $0.13(0.04)$ \\
\hline 195 & $0.27(<.0001)$ & $-0.04(0.53)$ & $-0.06(0.34)$ & $0.16(0.01)$ \\
\hline 196 & $0.36(<.0001)$ & $0.00(0.98)$ & $-0.04(0.48)$ & $0.15(0.02)$ \\
\hline 201 & $0.34(<.0001)$ & $-0.05(0.42)$ & $-0.09(0.18)$ & $0.08(0.21)$ \\
\hline 206 & $0.39(<.0001)$ & $-0.02(0.76)$ & $-0.08(0.22)$ & $0.13(0.05)$ \\
\hline 209 & $0.45(<.0001)$ & $-0.11(0.08)$ & $-0.15(0.02)$ & $0.19(0.003)$ \\
\hline
\end{tabular}

Values are correlation coefficient ( $p$-value). $P$-values $<0.05$ are bolded

${ }^{a}$ Estimated from the Phillips 1989 equation. Re-scaled and natural-log transformed

than women who do not develop GDM [42-44]. Given the higher level of circulating total lipids among women with GDM in our sample, we expected that levels of the POPs, PBB 153 and PCBs, would be higher because in this sample and in previous studies of non-pregnant adults [45], circulating lipid levels are positively correlated with circulating POPs. However, the levels of PCBs were lower among women with GDM compared to those without GDM. Thus, it may be the case that women who developed GDM sequestered PCBs to a greater extent in other lipid compartments such as adipose tissue, and thus have lower levels of circulating PCBs.

Studies generally assume that in fasting individuals, serum samples can be used to monitor POPs because POPs are equally distributed in all lipid compartments [46]. It is also usually assumed that adjustment for serum lipids in non-fasting individuals can mirror these fasting equilibrium conditions [47]. However, recent studies have cast doubt on the robustness of these assumptions [39, 48]. For example, a small $(n=7)$ study comparing PCB concentrations in serum lipids, visceral 


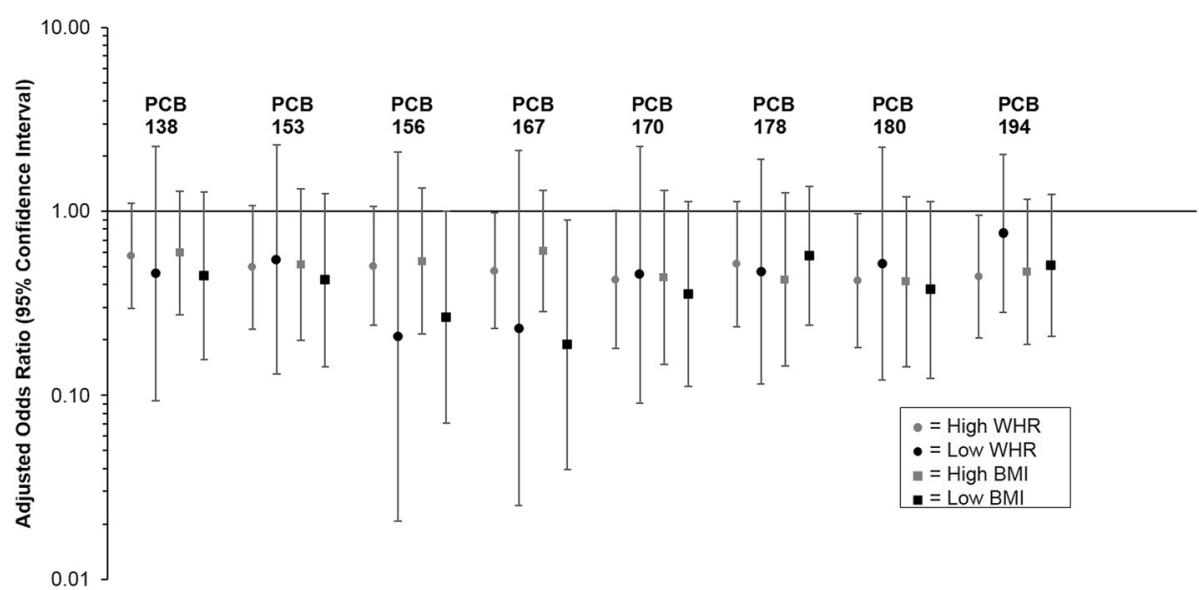

Fig. 3 Association between select pre-pregnancy serum polychlorinated biphenyl (PCB) congeners and gestational diabetes stratified by waist-to-height ratio (WHR $\leq 0.5$ versus WHR $>0.5$ ) and by body mass index $\left(B M l<25.0 \mathrm{~kg} / \mathrm{m}^{2}\right.$ versus $\mathrm{BMl} \geq 25.0 \mathrm{~kg} / \mathrm{m}^{2}$ ). Values are odds ratios and $95 \%$ confidence intervals from multivariable binary logistic regression, adjusted for age and total serum lipids estimated from the Phillips 1989 equation

fat, and subcutaneous fat, found a "reasonably good correlation" between serum PCBs and subcutaneous fat PCBs for half of participants, but only a weak correlation for the other half [48]. They also reported a tendency toward higher levels of highly chlorinated PCBs in visceral fat compared to subcutaneous fat in half of participants, but in the other participants they found similar levels in these compartments or higher levels in subcutaneous compared to visceral fat [48]. A more recent, larger study $(n=189)$ also reported higher levels of POPs in visceral compared to subcutaneous adipose tissue, but did not assess circulating levels and did not assess PCBs [49]. An operative cohort study of women aged 18-44 years found biological-medium-specific effects of POPs on endometriosis: for example, PCB 151 in omentum fat was significantly associated with increased risk of endometriosis, but not PCB 151 in serum [50]. Clearly more research is needed to test the robustness of common assumptions that serum levels of PCBs reflect levels found in other lipid compartments.

Related to this, we found that women who developed GDM had higher levels of visceral adiposity, as measured using waist-to-height ratio, relative to women who did not develop GDM. This may partially explain the lower circulating levels of PCBs, particularly the more highly chlorinated PCBs. Studies among non-pregnant

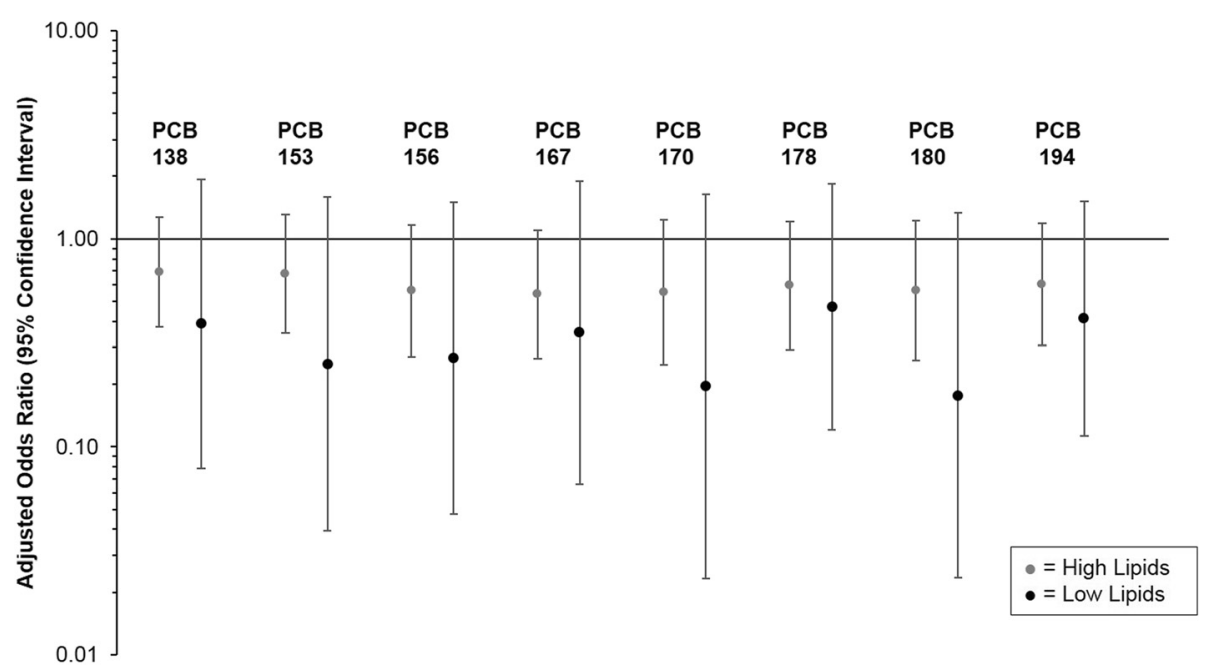

Fig. 4 Association between select pre-pregnancy serum polychlorinated biphenyl (PCB) congeners and gestational diabetes stratified by total serum lipids estimated from the Phillips 1989 equation (total serum lipids < median [599.6 mg/dl] versus total serum lipids $\geq$ median [599.6 mg/dl]). Values are odds ratios and $95 \%$ confidence intervals from multivariable binary logistic regression, adjusted for age and waist-to-height ratio 
adults have previously reported an inverse association between circulating levels of highly chlorinated PCBs and visceral and subcutaneous adipose tissue [51-53].

We did not find an association between PBB 153 and GDM, which is consistent with two other prospective analyses that did not find an association between PBBs and type 2 diabetes or insulin resistance $[15,16]$. One previous study in obese Japanese adults reported significantly lower levels of PCB 163/164 among individuals with type 2 diabetes (OR adjusted for sex, age, BMI, and total lipids 0.77 [0.62, 0.95]) [54]. They also found lower levels of PCB 153, though it was not statistically significant $(0.95[0.90,1.00])$ [54]. In contrast, a recent metaanalysis of total PCB levels (sum of PCB congeners) in non-pregnant adults found a significant positive association with risk of type 2 diabetes [18]. Further research is needed to disentangle the effects of specific PCB congeners versus $\mathrm{PCB}$ congener mixtures on diabetes risk.

Most research on the biological mechanisms underlying the association between PCBs and diabetes has focused on the dioxin-like $\mathrm{PCB}$ congeners. Interestingly, when the sum of dioxin-like PCB congeners and the sum of nondioxin-like PCB congeners were evaluated, the effect was stronger-though not statistically significant-for the nondioxin-like PCB congers. This is consistent with our results for individual congeners. Nonetheless, without adjustment for serum lipids, all associations were null. Remillard and Bunce [55] have speculated that null associations between PCBs and glucose disorders may relate to the opposing effects of commonly used herbicides such as 2,4-dichlorophenoxyacetic acid, which cause peroxisome proliferation $[56,57]$, and the potential antagonistic properties of dioxin-like compounds on peroxisome proliferator-activated receptors via activation of the aryl hydrocarbon receptor [58]. Future research should focus on the etiological mechanisms underlying potential effects of non-dioxin-like PCB congeners on glucose metabolism, and on the biological effects of differential partitioning of PCBs across lipid compartments, including adipose tissue and circulating lipid components.

A limitation of this study was that GDM was selfreported. The prevalence of GDM in this cohort was $10.9 \%$ compared to $8.1 \%$ as reported by women participating in the 2007-2008 Pregnancy Risk Assessment Monitoring System (PRAMS) when asked if they had "high blood sugar (diabetes) that started during this (most recent) pregnancy" [1]. Our participants were slightly older than the PRAMS cohort: $86.8 \%$ versus $67.4 \%$ $>25$ years old, respectively [1]. There are also significant differences between states in the prevalence of selfreported GDM: in the 2010 PRAMS survey, which included Texas but not Michigan, the prevalence of selfreported GDM was $10.0 \%$ in Texas compared to $8.7 \%$ overall [1]. While we did not validate self-reported GDM against medical records, previous studies have found good agreement between the two methods. For example, a validation study of the PRAMS questionnaire conducted in New York City (NYC) and Vermont in 2009 comparing self-reported GDM to medical record data reported a sensitivity of $88.4 \%$ in NYC and $82.0 \%$ in Vermont, specificity of $95.0 \%$ in NYC and $97.1 \%$ in Vermont, and positive predictive value of $49.5 \%$ in both sites [59]. While we recognize that it is possible that our estimate of GDM is an overestimate, it is unlikely that diagnosis or reporting of GDM are associated with the exposure (chemical levels) and, therefore, this is unlikely a major source of bias.

Other limitations beyond those associated with our observational design and use of self-reported GDM include potential confounding by other POPs such as organochlorine pesticides that may also be correlated with $\mathrm{PCBs}$, and residual confounding. In addition, given that this was an exploratory analysis, we did not adjust our p-values for multiple testing so cautious interpretation of results is needed.

\section{Conclusions}

To our knowledge, no study has evaluated the association between pre-pregnancy $\mathrm{PBB}$ or $\mathrm{PCB}$ concentrations and GDM. More studies are needed to improve our understanding of the associations of these POPs and this important pregnancy outcome given the strong association between GDM and future metabolic disease risk. These should focus on improving our understanding of the dynamic fluctuations of PCBs between lipid compartments in women preparing to conceive and throughout pregnancy.

\section{Additional file}

Additional file 1: Table S1. Summary of pre-pregnancy serum polybrominated and polychlorinated biphenyl levels. Table S2. Correlation between polychlorinated biphenyl (PCB) congeners. (DOCX $45 \mathrm{~kb}$ )

\section{Abbreviations}

ANOVA: analysis of variance; BMl: body mass index; Cl: confidence interval; EDTA: ethylenediaminetetraacetic acid; GDM: gestational diabetes; LOD: limit of detection; LIFE: Iongitudinal investigation of fertility and the environment; NYC: New York City; OR: odds ratio; POPs: persistent organic pollutants; PBBs: polybrominated biphenyls; PCBs: polychlorinated biphenyls; PRAMS: pregnancy risk assessment monitoring system.

\section{Competing interests}

The authors declare that they have no competing interests.

\section{Authors' contributions}

LMJ and DBB conceived the study. LMJ, DBB, RS, JM, CZ, and GMBL participated in the study design. LMJ performed the statistical analysis and drafted the manuscript. DBB, RS, JM, CZ, and GMBL contributed substantially to editing the manuscript. All authors read and approved the final manuscript. 


\section{Acknowledgements}

The LIFE Study was supported by the Intramural Research Program of the Eunice Kennedy Shriver National Institute of Child Health and Human Development (contracts \#N01-HD-3-3355; N01-HD-3-3356; N01-HD-3-3358). LMJ is supported by the Rollins School of Public Health Hubert Chair Fund. DBB is partially supported by the Emory Health and Exposome Research Center: Understanding Lifetime Exposures (HERCULES), funded by the National Institute of Environmental Health Sciences (P30 ES019776). None of the aforementioned funding sources had a role in the design, analysis, or writing of this article.

\section{Author details}

'Hubert Department of Global Health, Rollins School of Public Health, Emory University, Claudia Nance Rollins Building 7040-I, 1518 Clifton Rd NE, Atlanta, GA 30322, USA. ${ }^{2}$ Department of Environmental Health, Rollins School of Public Health, Emory University, Atlanta, GA, USA. ${ }^{3}$ Biostatistics and Bioinformatics Branch, Division of Intramural Population Health Research, Eunice Kennedy Shriver National Institute of Child Health and Human Development, Rockville, MD, USA. ${ }^{4}$ Glotech, Inc, Rockville, MD, USA. ${ }^{5}$ Division of Intramural Population Health Research, Eunice Kennedy Shriver National Institute of Child Health and Human Development, Rockville, MD, USA.

\section{Received: 25 August 2015 Accepted: 10 January 2016}

\section{Published online: 20 January 2016}

\section{References}

1. DeSisto CL, Kim SY, Sharma AJ. Prevalence estimates of gestational diabetes mellitus in the United States, pregnancy risk assessment monitoring system (PRAMS), 2007-2010. Prev Chronic Dis. 2014;11, E104.

2. Bellamy L, Casas JP, Hingorani AD, Williams D. Type 2 diabetes mellitus after gestational diabetes: a systematic review and meta-analysis. Lancet. 2009;373(9677):1773-9.

3. Boney CM, Verma A, Tucker R, Vohr BR. Metabolic syndrome in childhood: association with birth weight, maternal obesity, and gestational diabetes mellitus. Pediatrics. 2005;115(3):e290-6.

4. Clausen TD, Mathiesen ER, Hansen T, Pedersen O, Jensen DM, Lauenborg J, et al. High prevalence of type 2 diabetes and pre-diabetes in adult offspring of women with gestational diabetes mellitus or type 1 diabetes: the role of intrauterine hyperglycemia. Dia Care. 2008;31(2):340-6.

5. Keely EJ, Malcolm JC, Hadjiyannakis S, Gaboury I, Lough G, Lawson ML. Prevalence of metabolic markers of insulin resistance in offspring of gestational diabetes pregnancies. Pediatr Diabetes. 2008;9(1):53-9.

6. Malcolm JC, Lawson ML, Gaboury I, Lough G, Keely E. Glucose tolerance of offspring of mother with gestational diabetes mellitus in a low-risk population. Diabet Med. 2006;23(5):565-70.

7. McLean M, Chipps D, Cheung NW. Mother to child transmission of diabetes mellitus: does gestational diabetes program type 2 diabetes in the next generation? Diabet Med. 2006;23(11):1213-5.

8. Verma A, Boney CM, Tucker R, Vohr BR. Insulin resistance syndrome in women with prior history of gestational diabetes mellitus. J Clin Endocrinol Metab. 2002;87(7):3227-35.

9. Petry C. Gestational diabetes: origins, complications, and treatment. Boca Raton: CRC Press; 2014.

10. Solomon CG, Willett WC, Carey VJ, Rich-Edwards J, Hunter DJ, Colditz GA, et al. A prospective study of pregravid determinants of gestational diabetes mellitus. JAMA. 1997;278(13):1078-83.

11. Zhang C, Ning Y. Effect of dietary and lifestyle factors on the risk of gestational diabetes: review of epidemiologic evidence. Am J Clin Nutr. 2011;94 Suppl 6:1975S-9.

12. Saldana TM, Basso O, Hoppin JA, Baird DD, Knott C, Blair A, et al. Pesticide exposure and self-reported gestational diabetes mellitus in the Agricultural Health Study. Dia Care. 2007;30(3):529-34.

13. Saunders L, Kadhel P, Costet N, Rouget F, Monfort C, Thome JP, et al. Hypertensive disorders of pregnancy and gestational diabetes mellitus among French Caribbean women chronically exposed to chlordecone. Environ Int. 2014;68:171-6.

14. Zhang C, Sundaram R, Maisog J, Calafat AM, Barr DB, Buck Louis GM. A prospective study of prepregnancy serum concentrations of perfluorochemicals and the risk of gestational diabetes. Fertil Steril. 2015;103(1):184-9.
15. Vasiliu O, Cameron L, Gardiner J, Deguire P, Karmaus W. Polybrominated biphenyls, polychlorinated biphenyls, body weight, and incidence of adult-onset diabetes mellitus. Epidemiology. 2006;17(4):352-9.

16. Lee DH, Steffes MW, Sjodin A, Jones RS, Needham LL, Jacobs Jr DR. Low dose organochlorine pesticides and polychlorinated biphenyls predict obesity, dyslipidemia, and insulin resistance among people free of diabetes. PLoS One. 2011;6(1), e15977.

17. Lim JS, Lee DH, Jacobs DR. Association of brominated flame retardants with diabetes and metabolic syndrome in the U.S. population, 2003-2004. Dia Care. 2008;31(9):1802-7.

18. Wu H, Bertrand KA, Choi AL, Hu FB, Laden F, Grandjean P, et al. Persistent organic pollutants and type 2 diabetes: a prospective analysis in the nurses' health study and meta-analysis. Environ Health Perspect. 2013;121(2):153-61.

19. Buck Louis GM, Schisterman EF, Sweeney AM, Wilcosky TC, Gore-Langton $R E$, et al. Designing prospective cohort studies for assessing reproductive and developmental toxicity during sensitive windows of human reproduction and development-the LIFE Study. Paediatr Perinat Epidemiol. 2011;25(5):413-24

20. American Diabetes Association. Gestational diabetes mellitus. Dia Care. 2004;27 Suppl 1:S88-90.

21. Sjödin A, Jones RS, Lapeza CR, Focant JF, McGahee EE, Patterson DG. Semiautomated high-throughput extraction and cleanup method for the measurement of polybrominated diphenyl ethers, polybrominated biphenyls, and polychlorinated biphenyls in human serum. Anal Chem. 2004;76(7):1921-7.

22. Akins JR, Waldrep K, Bernert JT. The estimation of total serum lipids by a completely enzymatic summation method. Clin Chim Acta. 1989;184(3):219-26.

23. Phillips DL, Smith AB, Burse WW, Steele GK, Needham LL, Hannon WH. Halflife of polychlorinated biphenyls in occupationally exposed workers. Arch Environ Health. 1989:44(6):351-4.

24. Schisterman EF, Vexler A, Whitcomb BW, Liu A. The limitations due to exposure detection limits for regression models. Am J Epidemiol. 2006;163(4):374-83.

25. Richardson DB, Ciampi A. Effects of exposure measurement error when an exposure variable is constrained by a lower limit. Am J Epidemiol. 2003;157(4):355-63.

26. Calabrese EJ. Multiple chemical interactions. Boca Raton: CRC Press; 1990. p. 665.

27. Agency for Toxic Substances and Disease Registry. Toxicological profile for polychlorinated biphenyls. Atlanta: US Department of Health and Human Services; 2000.

28. Lohman TG, Roche AF, Martorell R. Anthropometric standardization reference manual. Champaign: Human Kinetics Books; 1988.

29. Garrow JS, Webster J. Quetelet's index (W/H2) as a measure of fatness. Int J Obes. 1984;9(2):147-53.

30. Obesity Education Initiative Expert Panel. Clinical guidelines on the identification, evaluation, and treatment of overweight and obesity in adults: the evidence report. Bethesda: US Department of Health and Human Services and National Institutes of Health; 1998.

31. World Health Organization. Obesity: preventing and managing the global epidemic. Geneva: World Health Organization; 2000.

32. World Health Organization. Waist circumference and waist-hip ratio, Report of a WHO expert consultation. Geneva: World Health Organization; 2008.

33. Ashwell M, Hsieh SD. Six reasons why the waist-to-height ratio is a rapid and effective global indicator for health risks of obesity and how its use could simplify the international public health message on obesity. Int J Food Sci Nutr. 2005;56(5):303-7.

34. Yaktine AL, Rasmussen KM. Weight gain during pregnancy: reexamining the guidelines. Washington, DC: National Academies Press; 2009.

35. Schafer UL. Analysis of incomplete multivariate data. Boca Raton: CRC press; 1997.

36. Rubin DB. Multiple imputation for nonresponse in surveys. Hoboken: John Wiley \& Sons; 2004.

37. Institute SAS. SAS/STAT(R) 14.1 User's Guide. Cary: SAS Institute; 2015.

38. Harel $\mathrm{O}$. The estimation of $\mathrm{R} 2$ and adjusted $R 2$ in incomplete data sets using multiple imputation. J Appl Stat. 2009;36(10):1109-18.

39. Schisterman EF, Whitcomb BW, Buck Louis GM, Louis TA. Lipid adjustment in the analysis of environmental contaminants and human health risks. Environ Health Perspect. 2005;113(7):853-7.

40. Rothman K, Greenland S, Lash TL. Modern epidemiology. Philadelphia: Lippincott Williams \& Wilkins; 2008. p. 130-1.

41. Goncharov A, Haase RF, Santiago-Rivera A, Morse G, McCaffrey RJ, Rej R, et al. High serum PCBs are associated with elevation of serum lipids and cardiovascular disease in a Native American population. Environ Res. 2008;106(2):226-39. 
42. Savvidou M, Nelson SM, Makgoba M, Messow CM, Sattar N, Nicolaides K First-trimester prediction of gestational diabetes mellitus: examining the potential of combining maternal characteristics and laboratory measures. Diabetes. 2010;59(12):3017-22.

43. Enquobahrie DA, Williams MA, Qiu C, Luthy DA. Early pregnancy lipid concentrations and the risk of gestational diabetes mellitus. Diabetes Res Clin Pract. 2005;70(2):134-42.

44. Sánchez-Vera I, Bonet B, Viana M, Quintanar A, Martín MD, Blanco P, et al. Changes in plasma lipids and increased low-density lipoprotein susceptibility to oxidation in pregnancies complicated by gestational diabetes: consequences of obesity. Metabolism. 2007;56(11):1527-33.

45. Patel CJ, Cullen MR, loannidis JP, Butte AJ. Systematic evaluation of environmental factors: persistent pollutants and nutrients correlated with serum lipid levels. Int J Epidemiol. 2012;41(3):828-43.

46. Pauwels A. Comparison of persistent organic pollutant residues in serum and adipose tissue in a female population in Belgium, 1996-1998. Arch Environ Contam Toxicol. 2000;39(2):265-70.

47. Phillips DL, Pirkle JL, Burse WW, Bernert Jr JT, Henderson LO, Needham LL. Chlorinated hydrocarbon levels in human serum: effects of fasting and feeding. Arch Environ Contam Toxicol. 1989;18(4):495-500.

48. Yu GW, Laseter J, Mylander C. Persistent organic pollutants in serum and several different fat compartments in humans. J Environ Public Health. 2011;2011:417980

49. Pestana D, Faria G, Sá C, Fernandes VC, Teixeira D, Norberto S, et al. Persistent organic pollutant levels in human visceral and subcutaneous adipose tissue in obese individuals - Depot differences and dysmetabolism implications. Environ Res. 2014;133:170-7.

50. Buck Louis GM, Chen Z, Peterson CM, Hediger ML, Croughan MS, Sundaram $R$, et al. Persistent lipophilic environmental chemicals and endometriosis: the ENDO Study. Environ Health Perspect. 2012;120(6):811-6.

51. Lee DH, Lind L, Jacobs DR, Salihovic S, van Bavel B, Lind PM. Associations of persistent organic pollutants with abdominal obesity in the elderly: The Prospective Investigation of the Vasculature in Uppsala Seniors (PIVUS) study. Environ Int. 2012;40:170-8.

52. Rönn M, Lind L, Bavel BV, Salihovic S, Michaëlsson K, Lind PM. Circulating levels of persistent organic pollutants associate in divergent ways to fat mass measured by DXA in humans. Chemosphere. 2011:85(3):335-43.

53. Roos V, Rönn M, Salihovic S, Lind L, Bavel BV, Kullberg J, et al. Circulating levels of persistent organic pollutants in relation to visceral and subcutaneous adipose tissue by abdominal MRI. Obesity. 2013;21(2):413-8.

54. Tanaka T, Morita A, Kato M, Hirai T, Mizoue T, Terauchi Y, et al. Congener-specific polychlorinated biphenyls and the prevalence of diabetes in the Saku Control Obesity Program (SCOP). Endocr J. 2011;58(7):589-96.

55. Remillard RB, Bunce NJ. Linking dioxins to diabetes: epidemiology and biologic plausibility. Environ Health Perspect. 2002;110(9):853-8.

56. Vainio H, Linnainmaa $K$, Kähönen M, Nickels J, Hietanen E, Marniemi J, et al. Hypolipidemia and peroxisome proliferation induced by phenoxyacetic acid herbicides in rats. Biochem Pharmacol. 1983;32(18):2775-9.

57. Wielandt A, Vollrath V, Manzano M, Miranda S, Accatino L, Chianale J. Induction of the multispecific organic anion transporter (cMoat/mrp2) gene and biliary glutathione secretion by the herbicide 2, 4, 5trichlorophenoxyacetic acid in the mouse liver. Biochem J. 1999;341:105-11.

58. Wang C, Xu CX, Krager SL, Bottum KM, Liao DF, Tischkau SA. Aryl hydrocarbon receptor deficiency enhances insulin sensitivity and reduces PPAR-a pathway activity in mice. Environ Health Perspect. 2011;119(12):1739-44.

59. Dietz P, Bombard J, Mulready-Ward C, Gauthier J, Sackoff J, Brozicevic P, et al. Validation of self-reported maternal and infant health indicators in the pregnancy risk assessment monitoring system. Matern Child Health J. 2014;18(10):2489-98.

\section{Submit your next manuscript to BioMed Central and we will help you at every step:}

- We accept pre-submission inquiries

- Our selector tool helps you to find the most relevant journal

- We provide round the clock customer support

- Convenient online submission

- Thorough peer review

- Inclusion in PubMed and all major indexing services

- Maximum visibility for your research

Submit your manuscript at www.biomedcentral.com/submit 